\title{
Uncertainties of GPM Microwave Imager Precipitation Estimates Related to Precipitation System Size and Intensity
}

\author{
AbisheK Adhikari, Chuntao LiU, AND LindSEy Hayden \\ Department of Physical and Environmental Sciences, Texas A\&M University-Corpus Christi, Corpus Christi, Texas
}

(Manuscript received 15 February 2019, in final form 24 June 2019)

\begin{abstract}
The uncertainties in the version 5 Global Precipitation Measurement (GPM) Microwave Imager (GMI) precipitation retrievals are evaluated via comparison with the radar-radiometer (so-called "Combined") retrievals between $40^{\circ} \mathrm{S}$ and $40^{\circ} \mathrm{N}$. Results show the precipitation estimates are close ( $7 \%$ GMI overestimation) globally. However, some specific regions, such as central Africa, the Amazon, the Himalayan region, and the tropical eastern Pacific, show a large overestimation (up to 50\%) in GMI retrievals when compared to Combined retrievals. The uncertainties are further evaluated based on precipitation system properties, such as size and intensity of the system. GMI tends to underestimate precipitation volume when the system is relatively warm $(>250 \mathrm{~K})$ and small $\left(<200 \mathrm{~km}^{2}\right)$ due to the lack of ice scattering signatures. However, for large systems $\left(>2000 \mathrm{~km}^{2}\right)$, GMI-derived precipitation is typically higher than Combined over all surfaces. Based on the system properties, a simple bias correction methodology is proposed to implement in the Goddard Profiling Algorithm (GPROF) to reduce GMI biases. GMI precipitation volume is adjusted in each precipitation system based on the size and minimum $89 \mathrm{GHz}$ polarization-corrected temperature (PCT) over land and ocean separately. The overall GMI bias is reduced to $3 \%$, with significant improvement over land. The GMI biases (up to $50 \%$ ) over the previously mentioned regions are significantly or partially removed, becoming less than $20 \%$. This method also shows effectiveness in removing zonal and seasonal biases from GMI estimates. These results suggest the importance of utilizing the information of whole precipitation systems instead of individual pixels in the precipitation retrieval.
\end{abstract}

\section{Introduction}

Precipitation is a major component of hydrological cycle, as well as a main driver of the global atmospheric circulation (Chahine 1992; Trenberth et al. 2003). Correct measurement of global precipitation is thus a crucial step toward modeling the current variability and future climate change prediction (Chahine 1992; Huffman et al. 1995; Allen and Ingram 2002; Nesbitt et al. 2004; Randall et al. 2007). Precipitation measurement from spaceborne passive microwave remote sensing has become a powerful technique in the recent decades (Njoku 1982; Wilheit 1986; Prigent 2010). The changes in microwave radiances caused by hydrometeors via either emission/absorption (Wilheit et al. 1991) or scattering processes (Spencer et al. 1989) can be quantifiably related to clouds and precipitation. The emission/absorption from liquid hydrometeors causes brightness temperatures $\left(T_{b}\right)$ to increase, whereas the

Corresponding author: Abishek Adhikari, aadhikari1@islander. tamucc.edu scattering by hydrometeors causes a decrease in the microwave signal (Spencer et al. 1989; Gopalan et al. 2010; Kidd and Levizzani 2011; Costa et al. 2018). Over ocean, the additional emission signal from the precipitation can easily be distinguished from the radiatively cold background $(\sim 150 \mathrm{~K})$ because the radiometric signal over water bodies is low and homogeneous (emissivity $\sim 0.4-0.5$; Kummerow et al. 2011, 2001). However, over land, the surface emissivity is high (emissivity $\sim 0.8-0.9$ ) and heterogeneous, which leads to a warm background $(\sim 280 \mathrm{~K})$ and difficulty in observing the emission signal from the precipitation particles (Carr et al. 2015). Therefore, over land, the depression in the brightness temperatures at higher-frequency microwave channels caused by ice scattering is used instead to retrieve precipitation (Wang et al. 2009; Ferraro et al. 1998, 2013). Although the scattering-based technique is more indirect, it is a useful technique for understanding the amount of precipitation suspended in the atmosphere. The hydrometeor size, phase, number density, and depth of the layer are the main variables that affect the microwave brightness temperature, for all wavelengths. 
A $T_{b}$-rain rate relationship algorithm was first introduced by Wilheit et al. (1976) using a fairly simple regression model. Spencer (1984) developed a multiple regression model to estimate rain rate from microwave brightness temperatures from various frequency $(37,21,18,10.7 \mathrm{GHz})$ channels over crop fields. $37 \mathrm{GHz}$ was found to have more rain rate information than the other channels. The polarizationcorrected temperatures (PCT) at higher-frequency (i.e., $85.5 \mathrm{GHz}$ ) channels were found to be useful in eliminating the contrast between land and water, and the rain rate can be derived from PCT depression over land (Spencer et al. 1989). Further studies by Fulton and Heymsfield (1991) and Mugnai and Smith (1988) have shown that the brightness temperatures are dependent on both the liquid/ice water content and the vertical structure of the clouds. Based on the Special Sensor Microwave Imager (SSM/I) observations, Grody (1991) purposed the scattering index method, which uses scattering signatures to obtain rain rate, snow equivalent water content, and other parameters. The scattering index method was further expanded by Ferraro et al. (1994) by developing a more expansive set of screens that could be used to separate rainfall signal from various surface backgrounds, which was later used in the Tropical Rainfall Measuring Mission (TRMM) era over land. The sensitivity of the microwave brightness temperature to cloud properties makes it possible to retrieve the cloud vertical structure. Kummerow et al. (1996) purposed a satellitebased global microwave rainfall retrieval algorithm that utilized a multichannel physical approach for retrieving vertical structure and rainfall. The algorithm uses statistical inversion techniques based on the theoretical relationship between brightness temperature and rain rates, and is now known as the Goddard profiling (GPROF) algorithm. The GPROF algorithm has undergone significant and numerous improvements over time and has been implemented on data from various satellite-based passive microwave sensors, such as the SSM/I, TRMM Microwave Imager (TMI), and the most recent GPM Microwave Imager (GMI), among others.

The surface precipitation derived from the satellitebased microwave brightness temperatures are often inaccurate estimates with large biases (e.g., Masunaga et al. 2002; Nesbitt et al. 2004). The validation of such estimates is necessary on a global scale. The TRMM (Kummerow et al. 1998) satellite, launched in late 1997, provided a platform from which to estimate surface precipitation based on measurements from both passive (TMI) and active (Precipitation Radar; PR) sensors. Although a radar is an active sensor and its retrieval mechanism and algorithm are different from a radiometer's, it is a useful tool for validating surface precipitation and quantifying the errors and biases in radiometer precipitation estimation. Nesbitt et al. (2004) examined the performance of the TMI and evaluated the overall biases relative to the PR as a function of the storm type. This study revealed that the TMI overestimates the rain rate relative to the PR in mesoscale convective systems, and tends to underestimate in precipitation features without ice-scattering signatures, as indicated by $85 \mathrm{GHZ}$ PCT $>250 \mathrm{~K}$. Liu and Zipser (2014, hereafter LZ2014) compared TMI surface rain estimates with those of the PR using a pixel-to-pixel comparison at nadir and a precipitation system level comparison. The study showed relatively close correlation between the overall geographical distributions of TMI and PR, but reported large discrepancies over several specific regions such as central Africa, the Amazon, the tropical eastern Pacific, and the northern Indian Ocean. TMI observations have been shown to miss a large portion of the total precipitation formed over land via the warm rain process because of the difficulty in distinguishing the microwave radiative properties associated with this kind of rainfall from the complicated emissivity background over land. These studies found the rain volume to be underestimated by the TMI in most of the small systems (size $<200 \mathrm{~km}^{2}$ ) and overestimated in large mesoscale convective system (size $>2000 \mathrm{~km}^{2}$ ), over both land and ocean. Both studies suggested that the rainfall errors and biases are associated with storm size. The rain biases in the passive microwave algorithm can therefore be reduced using the properties of the precipitation system, instead of treating pixels independently (LZ2014).

After the successful era of TRMM, the Global Precipitation Measurement (GPM) Core Observatory satellite was launched in February of 2014, and has a higher orbital inclination $\left(65^{\circ}\right)$. The instruments on board GPM are similar to those on board TRMM, but with additional channels on both the active sensor [Dual-Frequency Precipitation Radar (DPR)] and the passive sensor (GMI), providing light rain as well as falling snow estimates (Hou et al. 2014; SkofronickJackson et al. 2017). The independent measurement of precipitation using two different sensors provides a platform capable of quantifying errors and biases on a global as well as regional scale. This study uses precipitation estimates from the GPM Combined Radar-Radiometer (hereafter, "Combined") product (Grecu et al. 2016) as a "ground truth" measurement for comparison purposes. Following the methodology developed by LZ2014, this study seeks to quantify 
GMI precipitation biases with respect to the Combined product and introduce a bias correction methodology to improve GMI precipitation estimates. This study utilizes 4 years (April 2014-March 2018) of the current version (version 5) of GPROF (Kummerow et al. 2015) and Combined precipitation estimates over the tropics and subtropics $\left(40^{\circ} \mathrm{S}-40^{\circ} \mathrm{N}\right)$ to address the following scientific questions:

- What are the differences in surface precipitation estimates between the GMI and Combined products?

- How are GMI and Combined precipitation retrievals different on a pixel to pixel level and for precipitation features of different sizes and intensities?

- How can precipitation system properties be utilized to reduce the GMI biases?

To answer the above questions, the first part of the study compares the estimated surface precipitation between GMI and Combined at a pixel-to-pixel as well as a precipitation system level. The second part of the study demonstrates the use of precipitation system properties to improve the GMI precipitation retrieval. This paper is organized as follows: section 2 presents the data and methods, section 3 presents a comparison of the two precipitation products, section 4 introduces a bias correction methodology, and the results of the bias correction, which is followed by the summary/conclusion in section 5 .

\section{Data and methods}

The GPM Core Observatory satellite is a low-orbit (407 km), highly inclined $\left(65^{\circ}\right)$, and non-Sun-synchronous satellite that was launched in February 2014. The onboard instruments include the DPR, which operates at $\mathrm{Ku}(13.6 \mathrm{GHz})$ and $\mathrm{Ka}(35.5 \mathrm{GHz})$ band frequencies, and the GMI, a multifrequency passive microwave imager. The GMI frequency ranges from 10.65 to $183.31 \mathrm{GHz}$, including both horizontal and vertical polarization at $18.7,36.64,89$, and $166 \mathrm{GHz}$, and only vertical polarization at 21.3 and $183 \pm 3$ and $183 \pm 7 \mathrm{GHz}$ (Hou et al. 2014; Skofronick-Jackson et al. 2017).

This study uses 4 years (April 2014-March 2018) of GMI and Combined precipitation products. The GMI precipitation retrievals are obtained from the 2A.GMI.GPROF algorithm, which uses brightness temperatures to estimate the surface precipitation. The GPM Combined product employs the 2B.DPRGMI algorithm. We have used the 2B DPR-GMI and 2A.GMI.GPROF products to define groups of contiguous precipitating pixels as precipitation features (PFs), which are known as Dual-Frequency
Precipitation Radar-Radar GMI Precipitation Features (DPR-RGPFs). Since the goal of this study is to summarize the uncertainties in the GMI precipitation retrievals, especially over relatively warm surface conditions where the majority of precipitation falls as liquid, the study domain covers only the tropics and subtropics between $40^{\circ} \mathrm{S}$ and $40^{\circ} \mathrm{N}$ over both land and ocean. A brief description of the GMI and Combined precipitation retrieval algorithms is given in the following subsections.

\section{a. GPM GMI products}

The GMI is a conically scanning, multifrequency microwave imager on board the GPM Core Observatory. Its cross-track swath width ranges from $931 \mathrm{~km}$ $( \pm 25 \mathrm{~km})$ for the 10.65 through $89 \mathrm{GHz}$ channels, to $826 \mathrm{~km}( \pm 22 \mathrm{~km})$ for the 166 and $183.31 \mathrm{GHz}$ channels. The spatial resolution on the Earth's surface also ranges from $25 \mathrm{~km}$ at $10 \mathrm{GHz}$ to $6 \mathrm{~km}$ at $183 \mathrm{GHz}$ (Draper et al. 2015). GMI measures microwave radiances in terms of brightness temperatures at thirteen channels. The microwave radiances at low-frequency channels $(37 \mathrm{GHz}$ or less) are more sensitive to the emission from liquid droplets, whereas at high frequencies $(37 \mathrm{GHz}$ or higher), radiances are primarily influenced by the scattering from ice hydrometeors. The GMI surface precipitation rate is retrieved from the brightness temperatures by the GPROF algorithm using a Bayesian approach.

While the passive microwave signals over land and ocean differ in sensitivity to precipitation, they are treated the same in the GPROF algorithm. The precipitation estimation only varies by using the appropriate database for the Bayesian retrieval that corresponds to the correct (one of 14) surface type. In the TRMM era, the algorithms did differ for land (by using a scattering index type approach), but this is not the case for the GPM. Over the oceans, surface emissivity is low, uniform, and radiometrically cold, therefore the GPROF precipitation retrieval algorithm over ocean relies mostly on emissivity characteristics. The radiation emitted by precipitation droplets is relatively warm with respect to the ocean background radiation, and thus can easily be separated. However, over land, surface emissivity is high and varies significantly with surface conditions such as temperature, soil moisture, surface type, etc. (Ferraro et al. 2013), which makes it difficult to differentiate the radiation emitted by the precipitation drops from that emitted by the surface. Therefore, microwave precipitation retrievals over the land are primarily based on ice-scattering signatures. Although the ice-scattering signatures are less well related to precipitation, the precipitation signal is more 
easily distinguished over a warm surface background (Petković and Kummerow 2015). The scattering-based method infers precipitation from the amount of ice in the cloud, assuming that the ice would eventually fall to the surface and that a large percentage of liquid precipitation at the surface is formed from melted ice particles. The GPROF algorithm utilizes a DPR retrieved cloud structure and surface precipitation rate as a priori knowledge, and it uses the Combined algorithm in building the profile database (Grecu et al. 2016). The details of GPROF algorithm are described in Kummerow et al. (2015).

\section{b. GPM Combined products}

The GPM Combined (radar-radiometer) algorithm is designed to derive precipitation using both DPR and GMI observations (Grecu et al. 2016). The GPM Combined algorithm is based on a physical (forward) model that estimates precipitation based on both DPR reflectivities and GMI brightness temperatures within the matched swath of DPR. The DPR, using Ku and Ka band, gleans the hydrometeor size distribution information as well as the associated attenuation in each range gate. The Combined algorithm relies on the information from the $\mathrm{Ku}$ band for heavy precipitation, where the Ka-band radar echoes are severely attenuated. The path integrated attenuation is further adjusted by using the brightness temperature information from GMI, because nonprecipitation cloud liquid water and water vapor are not directly detected by the DPR. The algorithm details are described in Grecu et al. (2016). In this study, for comparison purposes, the Combined product is considered as a benchmark to evaluate the GPROF precipitation retrievals, because it has been used as ground truth precipitation to build the a priori database for GPROF algorithm (Kummerow et al. 2015). It shows a good agreement with the Global Precipitation Climatology Project $(\mathrm{GPCP})$ in the tropics and midlatitudes $\left(40^{\circ} \mathrm{S}-40^{\circ} \mathrm{N}\right)$ (Grecu et al. 2016). Olson et al. (2016) validated Combined surface precipitation rate (V04) with MultiRadar Multi-Sensor (MRMS) system (Zhang et al. 2016) gauge calibrated precipitation rate over the continental United States and estimated a correlation of 0.84 . They also found that the surface precipitation estimates between Combined and the GPCP have similar distributions over the tropics and subtropics with some biases over high latitudes. Furthermore, the validation of Combined surface precipitation with MRMS shows that the current version (V05) of Combined product has a significant reduction in biases $(-3.6 \%)$ when compared to its previous version $(61 \%)$ (Skofronick-Jackson et al. 2018; Petersen et al. 2019).

\section{Comparison of GMI and Combined surface precipitation}

The geographical distribution of mean unconditional precipitation estimated by Combined (Fig. 1a) and GMI (Fig. 1b) show a similar climatology. Note that the mean unconditional precipitation is estimated by dividing total precipitation volume $\left(\mathrm{mm} \mathrm{h}^{-1} \mathrm{~km}^{-2}\right)$ by the total area of sample pixels (rain or no rain) in each $5^{\circ}$ longitude $\times 2^{\circ}$ latitude grid box. The estimated mean zonal precipitation from the Combined (GMI) over $40^{\circ} \mathrm{S}-$ $40^{\circ} \mathrm{N}$ is $1036 \mathrm{~mm} \mathrm{yr}^{-1}\left(1105 \mathrm{~mm} \mathrm{yr}^{-1}\right)$. The zonal mean precipitation rate estimated by GMI overestimates that of Combined, and the difference is even higher over land than over ocean (see Table 1, Figs. 1c,d). The GMI overestimates the Combined by $3.9 \%$ over ocean and by $17.2 \%$ over land. The GMI derived precipitation rate is up to $50 \%$ higher over central Africa, the Himalayan and Tibetan regions, the tropical eastern Pacific, and central South America than the Combined. Generally, central African storms tend to have relatively large ice particles aloft that lead to greater depressions in brightness temperatures, resulting in an overestimation of TMI precipitation (LZ2014), which might also lead to multiple scattering problems with the DPR. Over the Amazon region, GMI shows an overestimation of $50 \%$, which contradicts the previous result of TMI presented by LZ2014. Though it is expected that the GMI would have difficulties to detect warm rain over the Amazon, there are many features having nonzero GMI precipitation but zero Combined precipitation. It is possible that part of the overestimation comes from false detection of GMI, because a large portion of features over the Amazon region show nonzero GMI precipitation, but zero Combined precipitation volume (figure not shown). Another source of overestimation could be from the overresponse of GPROF to the ice scattering signal over the region. Over certain regions, such as the Mediterranean, the GMI underestimates the Combined by more than $20 \%$. Lack of ice scattering due to large amount of warm rainfall (Liu and Zipser 2009) and congestus (Wall et al. 2013) lead to an underestimation of precipitation by GMI over the Mediterranean region. Even in deep clouds, ice scattering signals are not always associated with precipitation (Costa et al. 2018). The GMI and Combined precipitation statistics over various global regions, such as $20^{\circ} \mathrm{S}-20^{\circ} \mathrm{N}$ and $20^{\circ}-40^{\circ} \mathrm{N} / \mathrm{S}$ over land and ocean, are also presented in Table 1. This leads us to believe that, even though the geographic distribution is similar between the two retrieval methods, GMI derived precipitation tends to overestimate that of Combined in several land and oceanic regions. Thus, the differences are further investigated 
(a) Mean Combined annual precipitation (201404-201803) $\mathrm{mm} / \mathrm{yr}$

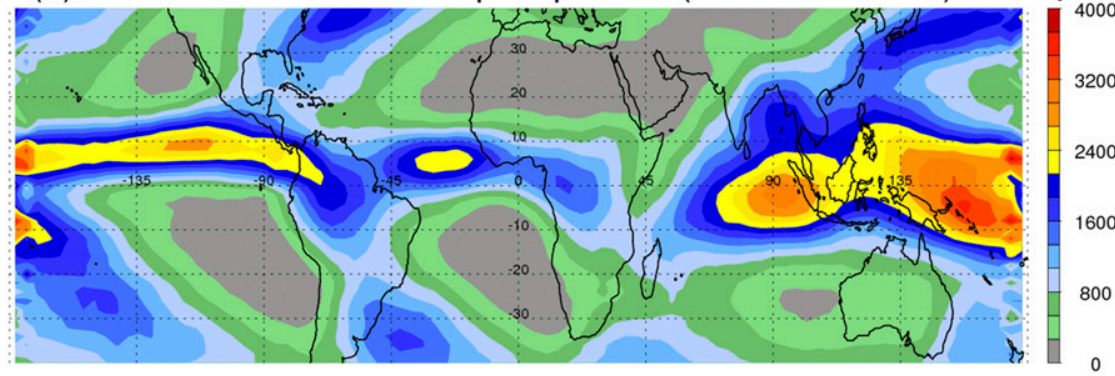

(b) Mean GMI annual precipitation (201404-201803) mm/yr

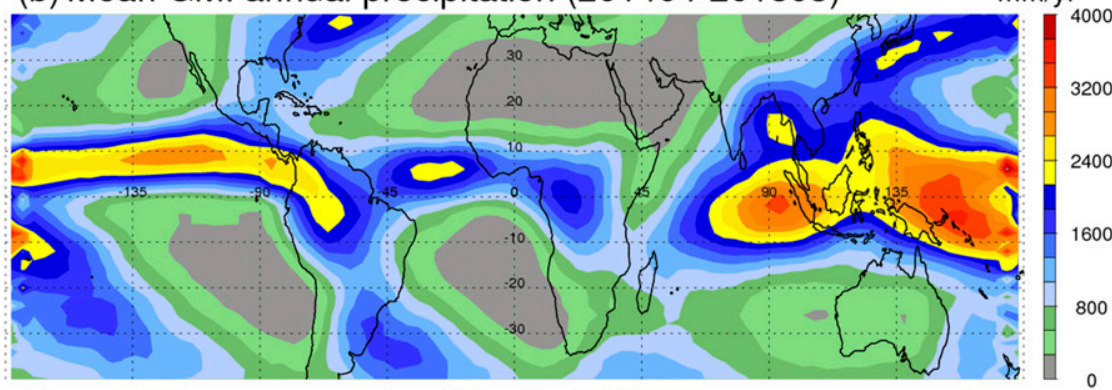

(c)

Combined - GMI

$\mathrm{mm} / \mathrm{yr}$

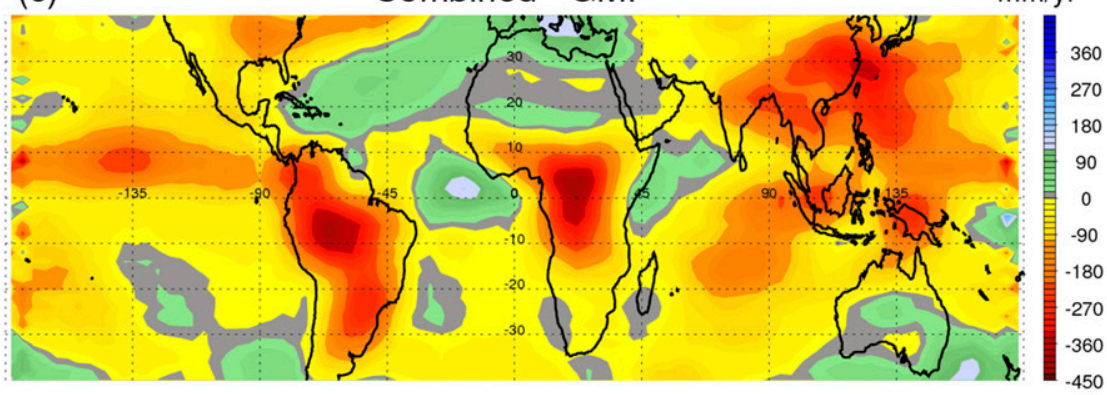

(d)

(Combined - GMI) / Combined

$\%$

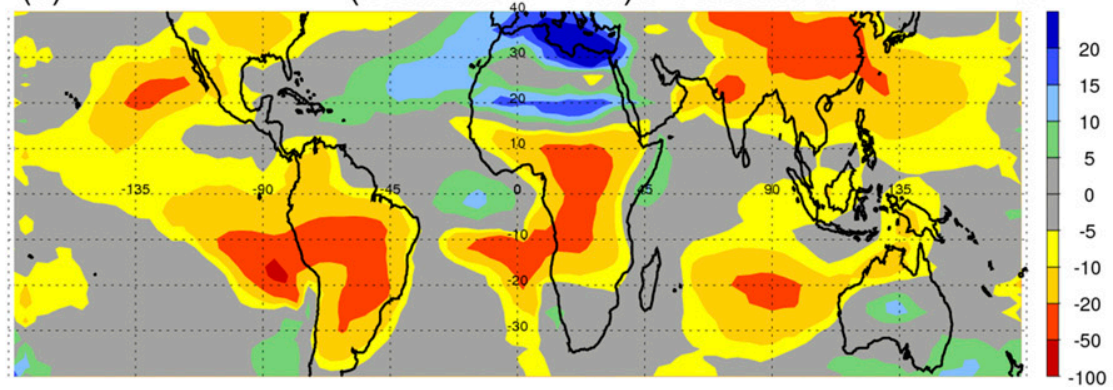

FIG. 1. Geographical distribution of mean unconditional precipitation rates estimated by GPM (a) Combined products, (b) GMI, and the (c) differences and (d) percentage differences between combined and GMI. The distribution is generated on a $5^{\circ} \times 2^{\circ}$ longitude and latitude grid. The GMI data used are only those within the Combined (DPR) matched swath.

based on a pixel-to-pixel comparison at nadir and on a precipitation feature level as conducted in LZ2014.

\section{a. Pixel-to-pixel comparisons between Combined and GMI}

The GMI near-surface precipitation pixels are matched with the Combined (i.e., DPR swath) pixels using the nearest neighbor method. The differences in occurrence and contribution of near-surface precipitation rates between the matched swaths of GMI and Combined are presented in Fig. 2. Note that the occurrence and contributions of near-surface precipitation rate are estimated in $1 \mathrm{~mm} \mathrm{~h}^{-1}$ bins from $40^{\circ} \mathrm{S}$ to $40^{\circ} \mathrm{N}$ over land and ocean separately. Munchak and Skofronick-Jackson (2013) 
TABLE 1. Mean unconditional annual precipitation rates estimated by Combined and GMI products over various global regions.

\begin{tabular}{|c|c|c|c|c|c|c|}
\hline Coverage & Surface type & Combined $\left(\mathrm{mm} \mathrm{yr}^{-1}\right)$ & GMI $\left(\mathrm{mm} \mathrm{yr}^{-1}\right)$ & $\%$ diff & $\mathrm{GMI}_{\text {corrected }}\left(\mathrm{mm} \mathrm{yr}^{-1}\right)$ & $\%$ diff \\
\hline \multirow[t]{3}{*}{$40^{\circ} \mathrm{S}-40^{\circ} \mathrm{N}$} & Land + ocean & 1036 & 1105 & 6.66 & 1067 & 3.0 \\
\hline & Ocean & 1126 & 1170 & 3.9 & 1145 & 1.7 \\
\hline & Land & 796 & 933 & 17.2 & 855 & 7.4 \\
\hline \multirow[t]{3}{*}{$20^{\circ}-40^{\circ} \mathrm{N} / \mathrm{S}$} & Land + ocean & 763 & 810 & 6.2 & 762 & -0.1 \\
\hline & Ocean & 871 & 904 & 3.8 & 863 & -0.9 \\
\hline & Land & 503 & 584 & 16.1 & 521 & 3.6 \\
\hline \multirow[t]{3}{*}{$20^{\circ} \mathrm{S}-20^{\circ} \mathrm{N}$} & Land + ocean & 1309 & 1401 & 7.1 & 1370 & 4.7 \\
\hline & Ocean & 1365 & 1420 & 4.0 & 1412 & 3.4 \\
\hline & Land & 1142 & 1344 & 17.7 & 1247 & 9.2 \\
\hline
\end{tabular}

used the Special Sensor Microwave Imager/Sounder (SSMIS) as a proxy for various GPM-era sensors and evaluated the minimum detectable precipitation rate. They estimated that the GMI minimum detectable precipitation rate to be $\sim 0.2 \mathrm{~mm} \mathrm{~h}^{-1}$, however our results show that the GMI can detect precipitation rates down to $0.1 \mathrm{~mm} \mathrm{~h}^{-1}$ (Fig. 2). Over ocean, for precipitation rates below $2 \mathrm{~mm} \mathrm{~h}^{-1}$, GMI occurrence is higher than that of Combined. This is expected because the GMI can detect lighter $\left(<0.1 \mathrm{~mm} \mathrm{~h}^{-1}\right)$ precipitation whereas the DPR detects only down to $0.1 \mathrm{~mm} \mathrm{~h}^{-1}$ because of limitations in DPR detectability (Hamada and Takayabu 2016). The GMI occurrence is found to have a maximum $(\sim 0.2 \%)$ when the precipitation rate is below $\sim 1 \mathrm{~mm} \mathrm{~h}^{-1}$. However, the result is reversed when the precipitation rate is higher than $20 \mathrm{~mm} \mathrm{~h}^{-1}$. The GMI pixels underestimate the Combined (Fig. 2a) for all precipitation rates higher than $20 \mathrm{~mm} \mathrm{~h}^{-1}$. The occurrences of precipitation pixels are well matched and nearly identical when the precipitation rate is moderate $\left(2-20 \mathrm{~mm} \mathrm{~h}^{-1}\right)$. Over land, the occurrence pattern is similar to that over ocean, but the GMI overestimates (underestimates) all the precipitation below (above) $10 \mathrm{~mm} \mathrm{~h}^{-1}$ (Fig. 2b).

The contribution of precipitation from each $1 \mathrm{~mm} \mathrm{~h}^{-1}$ bin are also compared between matched swaths of GMI and Combined over land and ocean. The contribution of precipitation is the average annual rate $\left(\mathrm{mm} \mathrm{yr}^{-1}\right)$ during four years of observations in each $1 \mathrm{~mm} \mathrm{~h}^{-1}$ bin. Over ocean, $6-7 \mathrm{~mm} \mathrm{~h}^{-1}$ from both GMI and Combined contributes the highest amount of precipitation $\left(\sim 15 \mathrm{~mm} \mathrm{yr}^{-1}\right)$. The GMI measures higher contribution when the precipitation is light $\left(<1 \mathrm{~mm} \mathrm{~h}^{-1}\right)$, and lower contribution when the precipitation is heavy $\left(>10 \mathrm{~mm} \mathrm{~h}^{-1}\right)$ when compared to the Combined (Fig. 2a). However, over land, significant differences are observed. The GMI contribution is higher than that of Combined for all precipitation rate bins below $10 \mathrm{~mm} \mathrm{~h}^{-1}$. The GMI (Combined) has the highest contribution at $\sim 15 \mathrm{~mm} \mathrm{yr}^{-1}\left(10 \mathrm{~mm} \mathrm{yr}^{-1}\right)$ from the precipitation rate bins $5-6 \mathrm{~mm} \mathrm{~h}^{-1}$. For the heavier precipitation $\left(>10 \mathrm{~mm} \mathrm{~h}^{-1}\right)$, the GMI has a lower contribution when compared to the Combined (Fig. 2b). This leads us to believe that even though the geographical distributions of GMI and Combined are almost identical, there are still large differences when the data are presented at the pixel level. The pixel-to-pixel comparison at nadir is straightforward and provides the retrieval differences between two independent sensors at the same time and location. Although we have compared only the collocated pixels, there are still large uncertainties present. The different footprint area of the GMI and DPR leads to a strong nonuniform beam
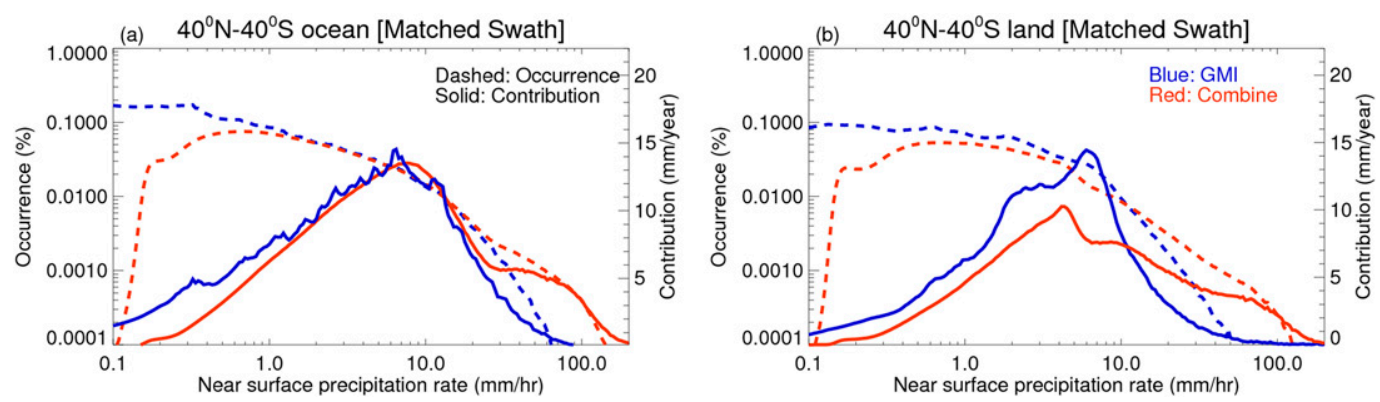

FIG. 2. Precipitation occurrences (dashed line) and contributions (solid line) from GMI (blue) and Combined (red) in each $1 \mathrm{~mm} \mathrm{~h}^{-1}$ precipitation rate bin (a) over ocean and (b) over land. Note that the occurrences and contributions are estimated by using matched swath orbital data from Combined and GMI. 

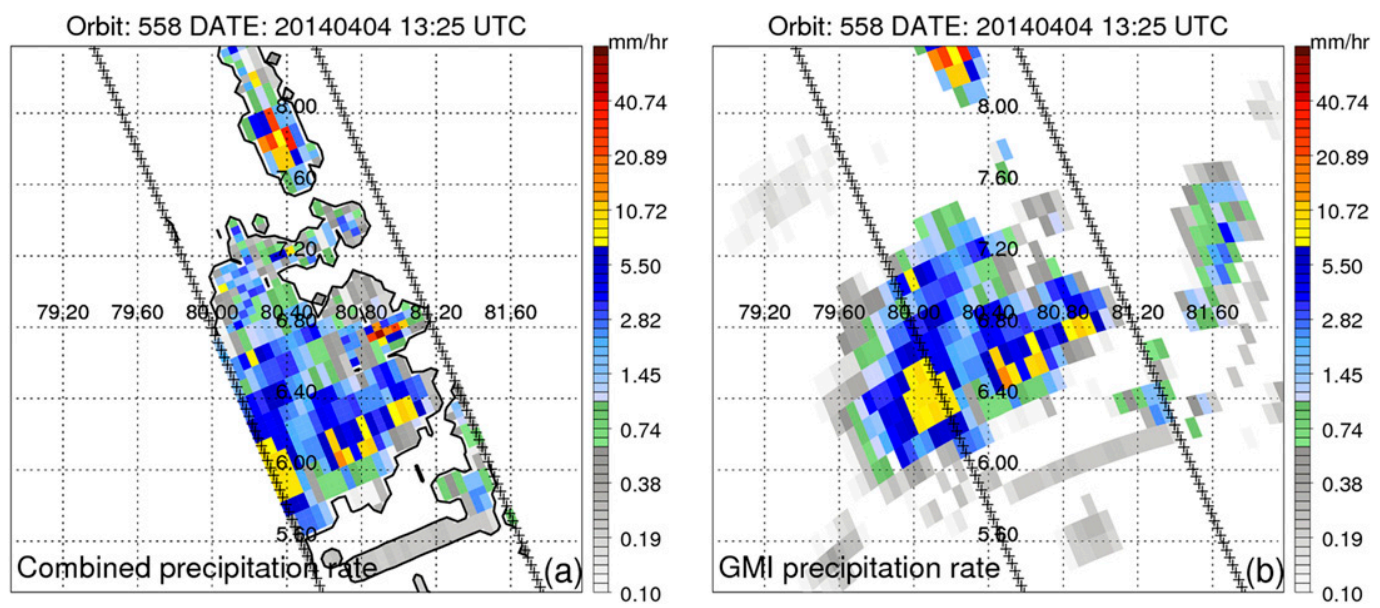

FIG. 3. (a) An example of DPR-RGPF over Ratnapur, Sri Lanka, at 1325 UTC 4 Apr 2014. The color fill represents precipitation rate $\left(\mathrm{mm} \mathrm{h}^{-1}\right)$ estimated by the Combined algorithm. The DPR-RGPF is defined by grouping the contiguous area of precipitation pixels (black contours) within the DPR swath (black crosses). (b) As in (a), but color fill shows GMI precipitation rate.

filling effect, which impacts the precipitation retrievals. The different scanning pattern could also lead to the mismatch between the GMI and the Combined pixels. The problems associated with different scanning geometries and footprint sizes between two types of sensors are well documented in LZ2014.

\section{b. Comparison based on precipitation feature properties}

The pixel-to-pixel comparison uncertainties can be overcome when the retrievals of total precipitation volume are compared at the precipitation system level by defining DPR-RGPFs. Four years (April 2014March 2018) of level-2 Combined orbital data from the GPM are used to define the DPR-RGPFs. Each DPR-RGPF is defined by grouping all the contiguous pixels of nonzero precipitation $\left(>0.1 \mathrm{~mm} \mathrm{~h}^{-1}\right)$ where either Combined or GMI detects at least four such pixels. Approximately 3 million features are identified as DPR-RGPFs during 4 years of GPM observation over $40^{\circ} \mathrm{S}-40^{\circ} \mathrm{N}$. Figure 3 a shows an example of DPR-RGPF and collocated GMI surface precipitation (Fig. 3b), where the mesoscale convective system (MCS) over Sri Lanka is well captured by both sensors. The Combined product shows a maximum surface precipitation rate $\sim 50 \mathrm{~mm} \mathrm{~h}^{-1}$, which is higher than the collocated GMI surface precipitation $\left(\sim 20 \mathrm{~mm} \mathrm{~h}^{-1}\right)$. The GMI swath width is wider than the DPR, so only the matched swath (i.e., DPR) is considered in this study (Fig. 3b). The properties of the features such as geographic location, volumetric precipitation, and area from both Combined and collocated GMI, and minimum $89 \mathrm{GHz}$ PCT (hereafter "min89PCT") from the GMI are summarized. The volumetric precipitation is the sum of the instantaneous precipitation rate times precipitation area, which does not include information on the vertical dimension of the raining area (Liu et al. 2008; Liu 2016). The GMI and Combined precipitation volumes are compared within each DPR-RGPF. By comparing the total precipitation volumes from GMI and Combined in DPR-RGPF, the beam filling and collocation effects no longer significantly impact results (LZ2014), and different precipitation system types and properties can be used to further explore GMI's retrieval biases with respect to Combined. Since the passive microwave signals over land and ocean differ in sensitivity to the precipitation, the comparison is also conducted separately over land and ocean. To investigate the differences between GMI and Combined, volumetric precipitation from GMI and Combined are intercompared in DPR-RGPFs of different sizes and intensities, indicated by area of the features and min89PCT. The ratio between Combined and GMI for systems of different sizes and PCTs are presented in two-dimensional histograms shown in Fig. 4. The geographical distributions of this fraction for DPR-RGPFs of small and large sizes, and warm and cold min89PCT are presented in Figs. 5 and 6, respectively, for features with greater GMI precipitation and features with greater Combined precipitation.

Over ocean, for smaller DPR-RGPFs sizes (area $<200 \mathrm{~km}^{2}$ ), most of the DPR-RGPFs have much higher Combined precipitation volume than the GMI when both detect the precipitation (Fig. $4 \mathrm{a}$ ). More than $80 \%$ of the small-sized systems have higher Combined precipitation than GMI precipitation over the oceanic 

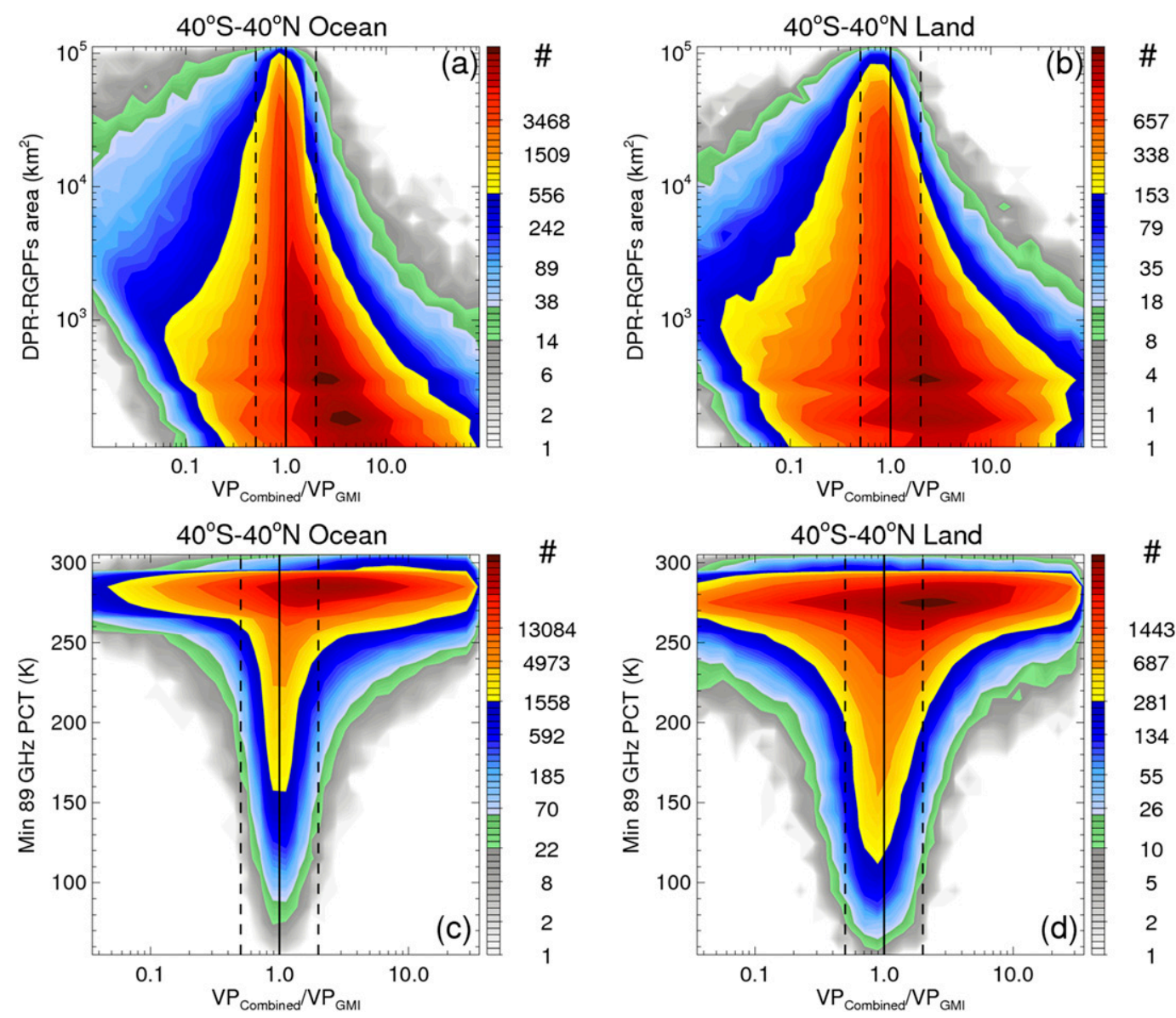

FIG. 4. Two-dimensional histogram of area and ratio of Combined to GMI volumetric precipitation of DPRRGPFs (a) over ocean and (b) over land. (c),(d) As in (a),(b), but displaying the two-dimensional histogram of min $89 \mathrm{GHz}$ PCT and ratio of Combined to GMI volumetric precipitation of DPR-RGPFs for land and ocean, respectively. Dashed lines are the ratios of 0.5 and 2 .

regions. One possible reason for this is that, while defining precipitation features, only pixels with precipitation rates greater than $0.1 \mathrm{~mm} \mathrm{~h}^{-1}$ have been used, so the precipitation rates lower than $0.1 \mathrm{~mm} \mathrm{~h}^{-1}$ from the GMI might be excluded when using this method. Small DPR-RGPFs with higher GMI precipitation volume are found only over stratocumulus regions where the DPR misses the light precipitation due to the sensitivity issue. However, for large DPRRGPFs (area $>200 \mathrm{~km}^{2}$ ), GMI tends to overestimate the Combined (Fig. 4a). A large proportion $(>60 \%)$ of large systems with higher GMI precipitation fractions are especially found over the northern and southern Pacific Ocean, southern Atlantic Ocean, and Indian Ocean (Fig. 5d).

Over land, small DPR-RGPFs show higher Combined precipitation volume than the GMI (Fig. 4b). There are large proportions $(>40 \%)$ of small systems in the continental regions such as central Africa, Himalayan regions, Argentina, and Pakistan, where GMI overestimates the Combined precipitation (Fig. 5b). The GMI and Combined volumetric precipitation ratios are more consistent for large systems than for small DPR-RGPFs. However, the majority of the land regions have at least $50 \%$ of the large DPR-RGPFs where GMI dominates the Combined precipitation. This is the reason why GMI estimated annual mean precipitation rate $\left(933 \mathrm{~mm} \mathrm{yr}^{-1}\right)$ over land is higher $(17.2 \%)$ than Combined $\left(796 \mathrm{~mm} \mathrm{yr}^{-1}\right)$ (Table 1).

The precipitation volume differences are further analyzed based on the min89PCT. Two-dimensional histograms of min89PCT and the ratio of Combined to GMI volumetric precipitation of DPR-RGPFs are plotted for systems over ocean (Fig. 4c) and over land (Fig. 4d). Note that the GMI precipitation retrieval algorithm over ocean primarily relies on emissivity characteristics whereas the land algorithm mostly relies on ice scattering signatures. 
Percent of small DPR-RGPFs $\left(\right.$ size $<200 \mathrm{~km}^{2}$ ) with VP $\mathrm{Combined} / \mathrm{VP}_{\mathrm{GMI}}>1 \quad$ (a) $\%$

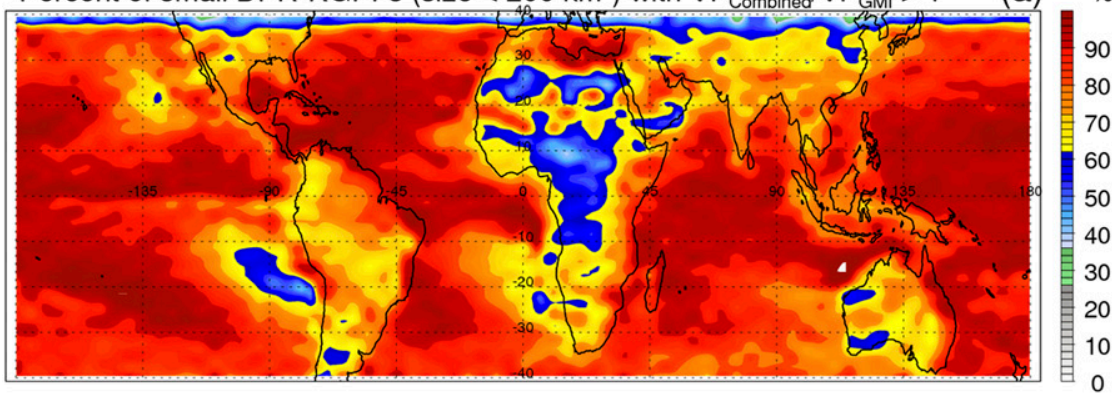

Percent of small DPR-RGPFs $\left(\right.$ size $<200 \mathrm{~km}^{2}$ ) with $\mathrm{VP}_{\text {Combined }} / \mathrm{VP}_{\mathrm{GMl}}<1 \quad$ (b) $\%$

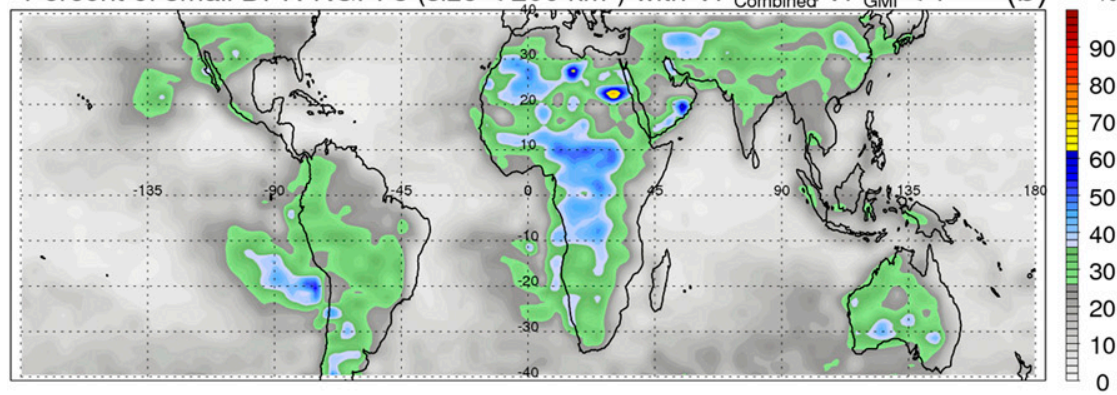

Percent of large DPR-RGPFs (size $>2000 \mathrm{~km}^{2}$ ) with $\mathrm{VP}_{\text {combined }} / \mathrm{VP}_{\mathrm{GMI}}>1 \quad$ (c) \%

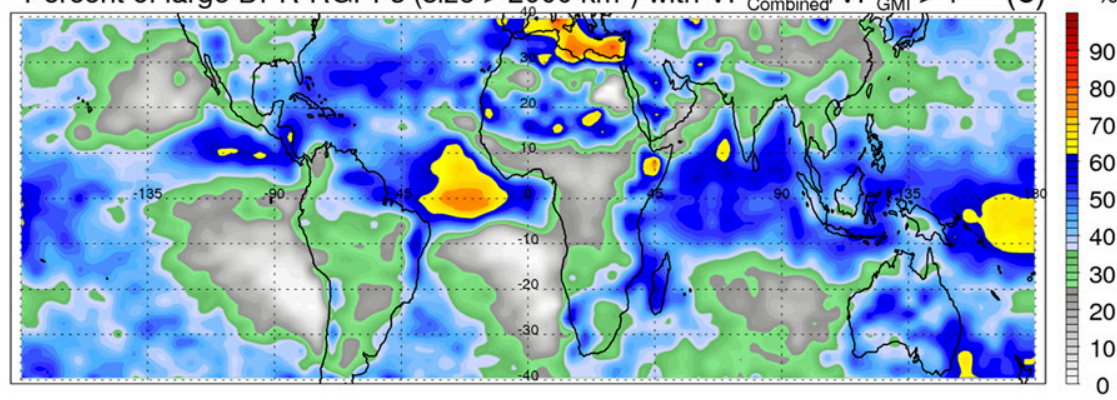

Percent of large DPR-RGPFs (size $\left.>2000 \mathrm{~km}^{2}\right)$ with $\mathrm{VP}_{\text {Combined }} / \mathrm{VP}_{\mathrm{GMI}}<1 \quad$ (d) \%

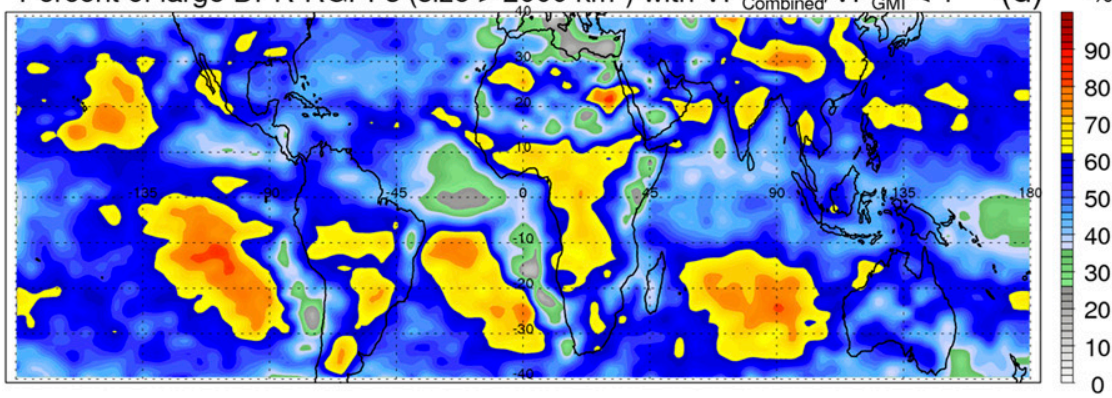

FIG. 5. Geographical distribution of the fractions of small (area $<200 \mathrm{~km}^{2}$ ) DPR-RGPFs with Combined volumetric precipitation is (a) larger and (b) smaller than GMI volumetric precipitation. (c),(d) As in (a),(b), but for larger $\left(>10000 \mathrm{~km}^{2}\right)$ DPR-RGPF area. The distributions are shown on a $5^{\circ} \times 2^{\circ}$ longitude and latitude grid.

Over ocean, for colder $(\min 89 \mathrm{PCT}<220 \mathrm{~K})$ DPRRGPFs, GMI and Combined show very similar volumetric precipitation (Fig. 4c). Min89PCT below $220 \mathrm{~K}$ is an indication of strong ice scattering signatures and significant optical depths of ice aloft that may be due to the presence of larger graupel or hail in tropical oceanic systems (Cecil et al. 2002; Toracinta et al. 2002). The reason for this consistency is that both GMI and Combined are highly sensitive to solid precipitation. However, there are some oceanic regions where the cold features have higher proportions $(>60 \%)$ of Combined precipitation volume than the GMI. They are mainly 

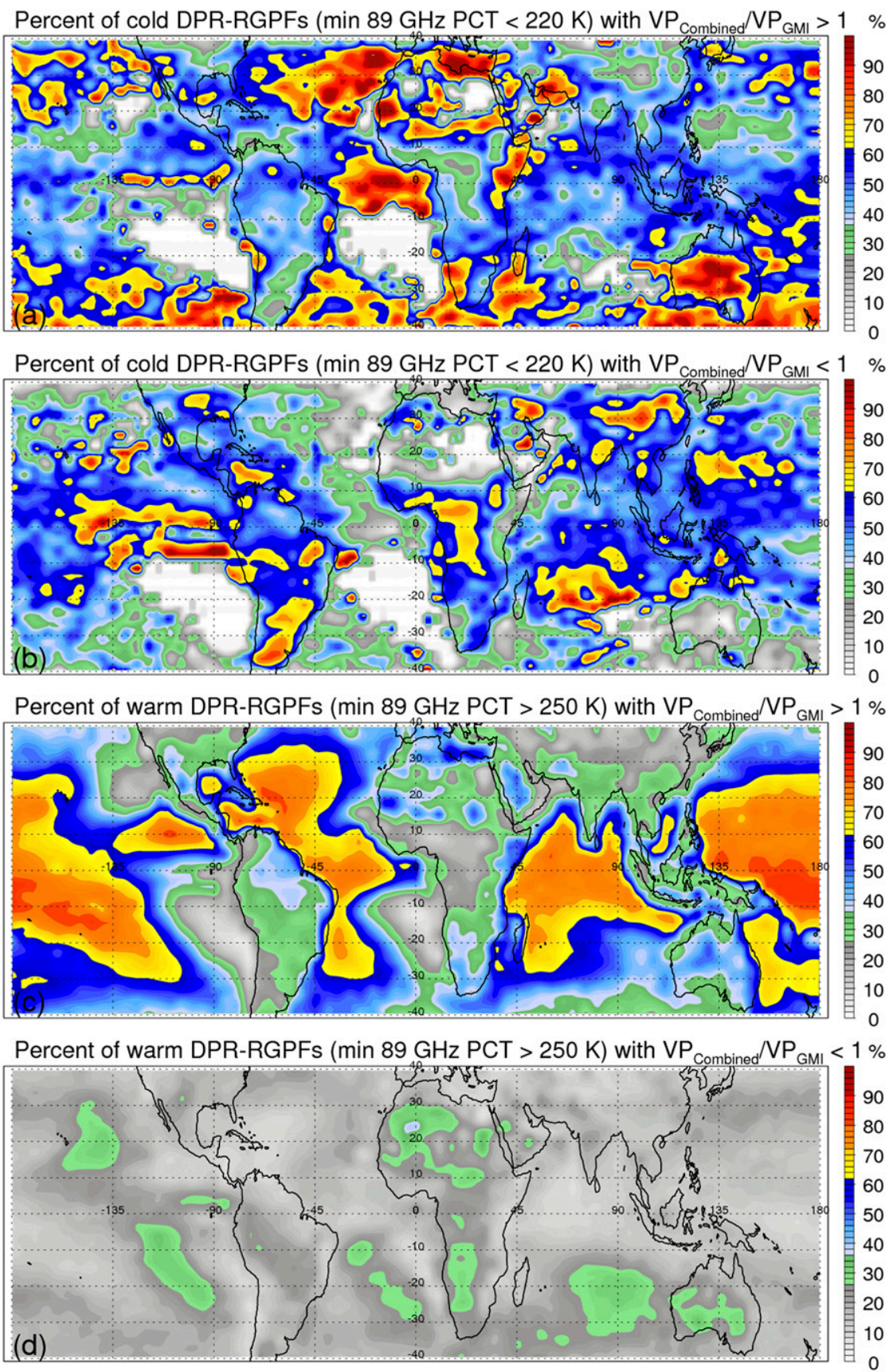

FIG. 6. Geographical distribution of the fractions of cold (PCT $<220 \mathrm{~K})$ DPR-RGPFs with Combined volumetric precipitation is (a) larger and (b) smaller than GMI volumetric precipitation. (c),(d) As in (a),(b), but for warm (PCT > 250 K) DPR-RGPFs. The distributions are shown in $5^{\circ} \times 2^{\circ}$ longitude and latitude boxes.

observed the Angola basin, the Atlantic Ocean, the Argentine basin, and the Southern Ocean (Fig. 6a). Other oceanic regions such as the central and northern Pacific, and Indian Ocean show higher proportions $(>60 \%)$ of GMI precipitation than Combined precipitation (Fig. 6b). However, for warm (min89PCT $>250 \mathrm{~K})$
DPR-RGPFs, most of the features show much higher Combined precipitation volume than GMI precipitation volume (Fig. 6c). It is possible that the overestimation in the Combined product is related to radar issues such as sidelobe contamination, which contribute a small amount of light precipitation in the Combined algorithm. 
The features that are associated with min89PCT $>$ $250 \mathrm{~K}$ are mostly the warm rain in the tropical ocean (Liu and Zipser 2009). A large portion (>70\%) of warm DPR-RGPFs that have higher Combined precipitation than GMI precipitation are observed in throughout the tropical $\left(20^{\circ} \mathrm{S}-20^{\circ} \mathrm{N}\right)$ oceans, except for some stratocumulus regions (Fig. 6c). The underestimation from the GMI over these regions is more likely due to the shallow systems, which do not have enough liquid droplets to produce a strong emission signal. Large amounts of warm rain (Liu and Zipser 2009) and congestus (Wall et al. 2013) in the tropical ocean show insufficient or no ice scattering signatures, which also leads to underestimation of precipitation by the GMI when compared to the Combined. There are some oceanic regions, such as the mid and southwestern Pacific Ocean, mid-Atlantic Ocean, and Indian Ocean, where a large portion ( $>30 \%$ ) of warm DPR-RGPFs that have higher GMI precipitation volume than the Combined are observed (Fig. 6d).

Over land, similar distributions, but relatively fewer features are observed when compared to their oceanic counterparts. The cold DPR-RGPFs show a nearly symmetrical distribution of the ratio of GMI to Combined volumetric precipitation (Fig. 4d). The geographical distribution shows a large portion $(70 \%)$ of DPR-RGPFs over some regions of Africa, such as the western Sahara, North Africa, Somalia, and Namibia, and other regions such as Pakistan and Chile have higher amounts of Combined precipitation than GMI precipitation. On the other hand, other continental regions such as Argentina, Tibet, Saudi Arabia, and Iraq show higher amounts of GMI precipitation (Fig. 6b). For warm DPR-RGPFs (min89PCT $>250 \mathrm{~K}$ ), Combined precipitation fraction is higher than that of GMI (Fig. 4d) and is distributed relatively evenly over the land (Fig. 6c).

Considering the Combined retrieval is the "truth" estimation, the abovementioned results show that large biases are still present in the GMI precipitation retrievals. Over various regions, the precipitation biases are found to be associated with size of the storm and its intensity, as described by the area and min89PCT. The different types of precipitation systems have different microphysical properties that need to be considered to correct the biases. Utilizing the information from the above findings, a bias correction methodology is purposed to overcome the uncertainties presented in the GMI precipitation retrievals. The system properties such as size, intensity, and volumetric are used to find the bias factors. The following section presents the description of the bias correction methodology and then assessments of bias corrected GMI precipitation.

\section{Bias correction methodology}

To correct the biases in the GMI precipitation retrieval, we have used the information that was learned from the TRMM observations. The TRMM observations show that TMI misses the majority of rain associated with small systems $\left(<200 \mathrm{~km}^{2}\right)$, due to the lack of ice scattering at $85 \mathrm{GHz}$ in warm rainfall. The rain volume from TMI is higher than from the PR for large systems $\left(>10000 \mathrm{~km}^{2}\right)$, due to beam filling effects and weak precipitation beyond the sensitivity of the PR (LZ2014). LZ2014 also highlighted that the bias presented in TMI and PR rain volume is related to precipitation systems, rather than the pixels independently. Following up on LZ2014, but using the GPM observations, this work is intended to use precipitation systems properties such as size and ice scattering information from min89PCT to correct the bias present in the GMI retrievals.

In each bin of system size and min89PCT, the precipitation volume from Combined and GMI is compared in each DPR-RGPF to calculate bias factor. Here, bias factor is defined as the fraction of Combined accumulated precipitation over GMI accumulated precipitation as a function of min89PCT and PF size (Fig. 7). Since, the passive microwave signals have different background over land and ocean, we calculate bias factor over land and ocean separately. Figure 7a shows that the bias factor fraction is as high as 10 for small and warm precipitation systems over the oceans. That indicates that the GMI estimates a very low fraction of total precipitation volume in warm and small systems when compared to the Combined. The majority of the rain associated with warm rain is missed by GMI because of the lack of ice scattering signatures at $89 \mathrm{GHz}$, and since the small systems might not be resolved by the large GMI footprint. However, for large systems, the GMI estimated precipitation volume is higher than the Combined by a factor of 2. Over land, similar biases are found; except for very deep and cold $(\min 89 \mathrm{PCT}<150 \mathrm{~K})$ systems, GMI overestimates the Combined. The large stratiform region associated with thick anvil clouds would be detected by GMI, but not by the DPR. The DPR either misses the small ice particles, which are beyond its sensitivity, or only detects hydrometeors at higher altitudes with no echoes in the near surface bins. This kind of system is more significant over land.

To examine how much the retrievals may be improved by using the additional information of the precipitation 

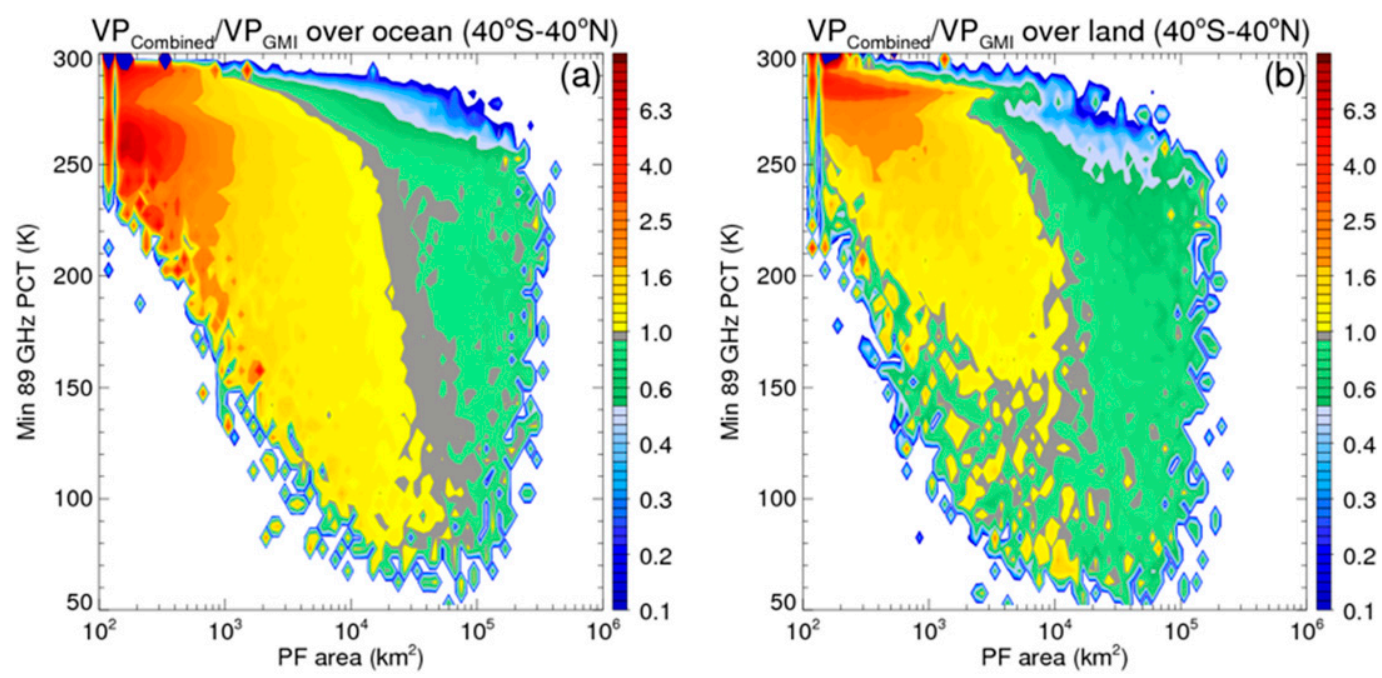

FIG. 7. Ratios between accumulated precipitation of Combined and GMI as compared to minimum $89 \mathrm{GHz}$ PCT and PF size (a) over ocean and (b) over land.

system size and intensity, the bias corrected GMI is calculated by using the following equation:

Bias corrected GMI $=$ GMI volumetric precipitation

$$
\times \text { bias factors. }
$$

GMI volumetric precipitation is multiplied by the bias factors in each bin of min89PCT and system size over land and ocean separately. The assessment of bias corrected GMI is presented in the following section.

\section{Assessment of bias corrected GMI precipitation}

It has been demonstrated in the earlier sections that the GMI volumetric precipitation underestimates the Combined for small $\left(\right.$ area $\left.<200 \mathrm{~km}^{2}\right)$ and warm $(\min 89 P C T>$ 250K) DPR-RGPFs, whereas for large systems (area $>$ $2000 \mathrm{~km}^{2}$ ), the GMI overestimates the Combined. For cold $(<220 \mathrm{~K})$ systems, both retrieval methods show consistent results (Fig. 4). The biases in the GMI retrievals are overcome using a bias correction methodology and an improved two-dimensional histogram similar to Fig. 4 is presented in Fig. 8. Over land and ocean, the ratio of GMI to Combined volumetric precipitation is almost symmetrical for both small and large systems (Figs. 8a,b). This shows a significant improvement of GMI precipitation amount for both small and large systems. However, for large systems, there are still a few DPR-RGPFs where the GMI slightly overestimates the Combined.

Similarly, over ocean, the corrected GMI-Combined ratios are almost symmetrical for both cold and warm systems indicating the huge improvement in precipitation estimation for warm systems (Fig. 8c). This is crucial because more than $70 \%$ of warm DPRRGPFs are over the tropical ocean where the GMI retrieval underestimates the Combined. This would significantly improve biases in oceanic GMI retrievals. Over land, although there are a few warm DPR-RGPFs that show higher GMI precipitation volume than that of Combined, the GMI is relatively consistent with the Combined for both warm and cold systems.

The mean unconditional precipitation rate retrieved by the GMI shows large discrepancies when compared with the Combined precipitation rates over some land and oceanic regions. The GMI overestimates the Combined over central South America, central Africa, eastern China, and the central Pacific by up to $450 \mathrm{~mm} \mathrm{yr}^{-1}$ or $50 \%$ (Figs. 1c,d). The bias corrected GMI mean unconditional precipitation rate over the aforementioned regions are close to the Combined precipitation rates (Figs. 9a,b). The biases are significantly reduced, for example, over central America $\left(\sim 10 \%\right.$ or $\left.90 \mathrm{~mm} \mathrm{yr}^{-1}\right)$, central Africa $\left(\sim 10 \%\right.$ or $\left.150 \mathrm{~mm} \mathrm{yr}^{-1}\right)$, eastern China $\left(<5 \%\right.$ or $\left.90 \mathrm{~mm} \mathrm{yr}^{-1}\right)$, and the central Pacific $(<5 \%$ or $\left.90 \mathrm{~mm} \mathrm{yr}^{-1}\right)$. Note that this method does not improve the precipitation over Australia and some stratocumulus regions because GPM sensors are shut down over Australia and the DPR does not capture very light precipitation over the stratocumulus regions. Also, over the Mediterranean Sea, even though the annual precipitation rate is very low $\left(300 \mathrm{~mm} \mathrm{yr}^{-1}\right)$, the GMI biases $(\sim 25 \%)$ are not improved. The estimated mean unconditional precipitation rate from the corrected GMI is more consistent with that of the Combined. For example, over $40^{\circ} \mathrm{S}-40^{\circ} \mathrm{N}$ land and ocean, the corrected 

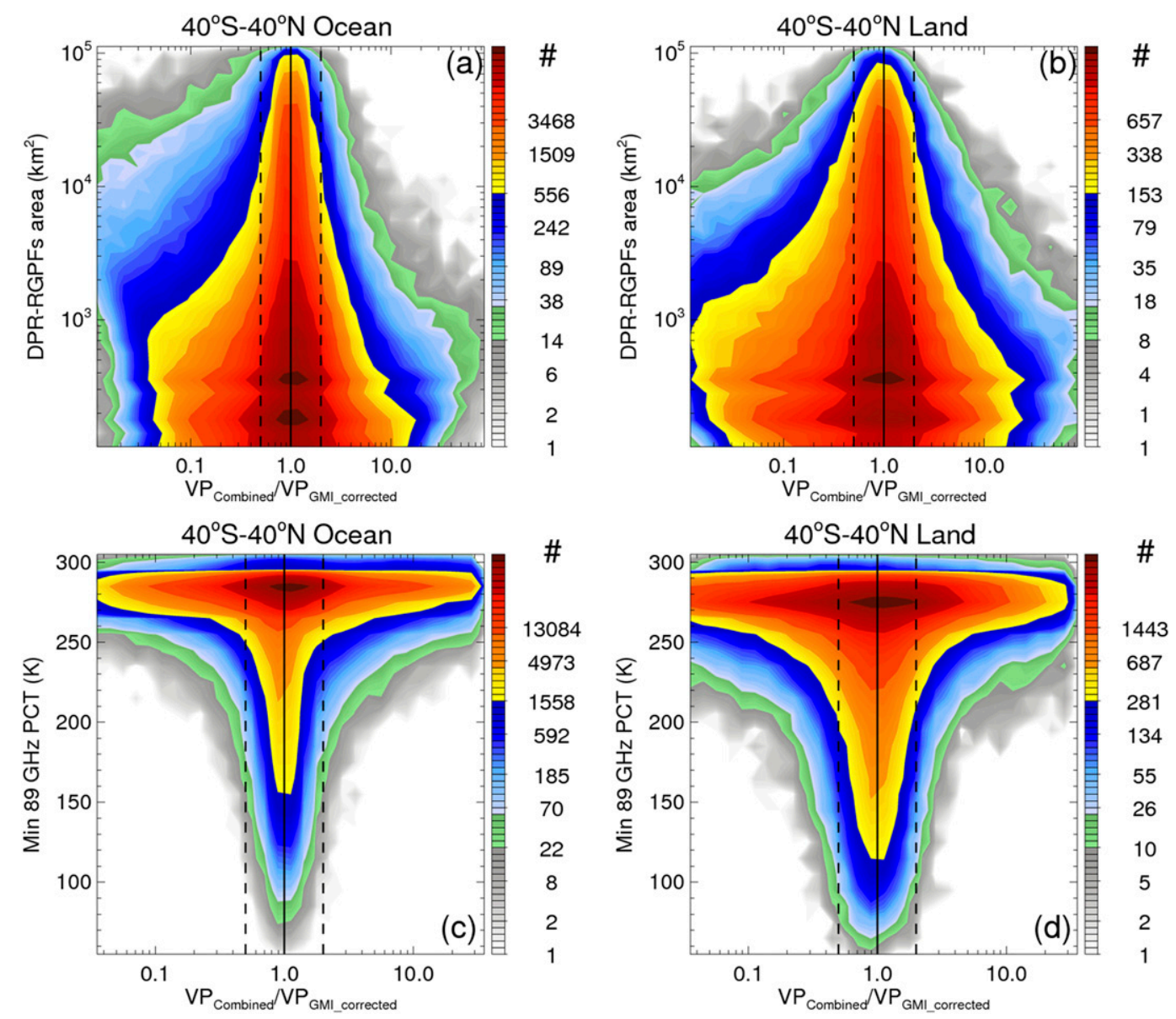

FIG. 8. Two-dimensional histogram of area and ratio of Combined and bias corrected GMI volumetric precipitation of DPR-RGPFs (a) over ocean and (b) over land. (c),(d) As in (a),(b), but the two-dimensional histogram of $\min 89 \mathrm{GHz}$ PCT and ratio of Combined and bias corrected GMI volumetric precipitation of DPR-RGPFs, respectively. Dashed lines are the ratios of 0.5 and 2 .

GMI estimated annual precipitation rate is about $1067 \mathrm{~mm} \mathrm{yr}^{-1}$, which is closer to the Combined estimation $\left(\sim 1036 \mathrm{~mm} \mathrm{yr}^{-1}\right)$ than the uncorrected GMI $\left(\sim 1105 \mathrm{~mm} \mathrm{yr}^{-1}\right)$ (Table 1$)$. The annual mean improvement is more substantial over land than over ocean. For example, the corrected GMI estimates mean annual precipitation to be about $855 \mathrm{~mm} \mathrm{yr}^{-1}$ over land from $40^{\circ} \mathrm{S}$ to $40^{\circ} \mathrm{N}$, which is more consistent with Combined $\left(796 \mathrm{~mm} \mathrm{yr}^{-1}\right)$ when compared to the uncorrected GMI $\left(\sim 933 \mathrm{~mm} \mathrm{yr}^{-1}\right)$. This brings down GMI biases from $17 \%$ to $7 \%$ when compared to the Combined. Over midlatitudes $\left(20^{\circ}-40^{\circ} \mathrm{N} / \mathrm{S}\right)$, the corrected GMI precipitation rate $\left(762 \mathrm{~mm} \mathrm{yr}^{-1}\right)$ is in good agreement with the Combined $\left(763 \mathrm{~mm} \mathrm{yr}^{-1}\right)$, especially when compared to the uncorrected GMI $\left(810 \mathrm{~mm} \mathrm{yr}^{-1}\right)$.

The mean zonal precipitation rates over land shows significant improvement when compared to their oceanic counterparts, where the zonal mean from the GMI, Combined, and corrected GMI are almost identical (Fig. 10). Tropical land shows a large difference in zonal mean between Combined and GMI. However, the zonal mean from bias corrected GMI over tropical land is close to the Combined, and becomes almost identical over midlatitude land (Fig. 10b). The estimated mean unconditional annual precipitation rate over tropical land from the corrected GMI is $\sim 1247 \mathrm{~mm} \mathrm{yr}^{-1}$, which is more consistent with the Combined $\left(1142 \mathrm{~mm} \mathrm{yr}^{-1}\right)$, when compared to the uncorrected GMI (1344 $\mathrm{mm} \mathrm{yr}^{-1}$ ) (Table 1, Fig. 10).

The joint seasonal and zonal variation of precipitation differences shows that the GMI overestimates the Combined, especially during the Northern Hemispheric summer and Southern Hemispheric winter (Fig. 11a). Over the Northern Hemispheric midlatitudes during all seasons except winter, GMI overestimates the Combined by $25 \%$. Over the tropics, GMI overestimates the precipitation by $\sim 20 \%$ during the spring season. In a large area over the Southern 

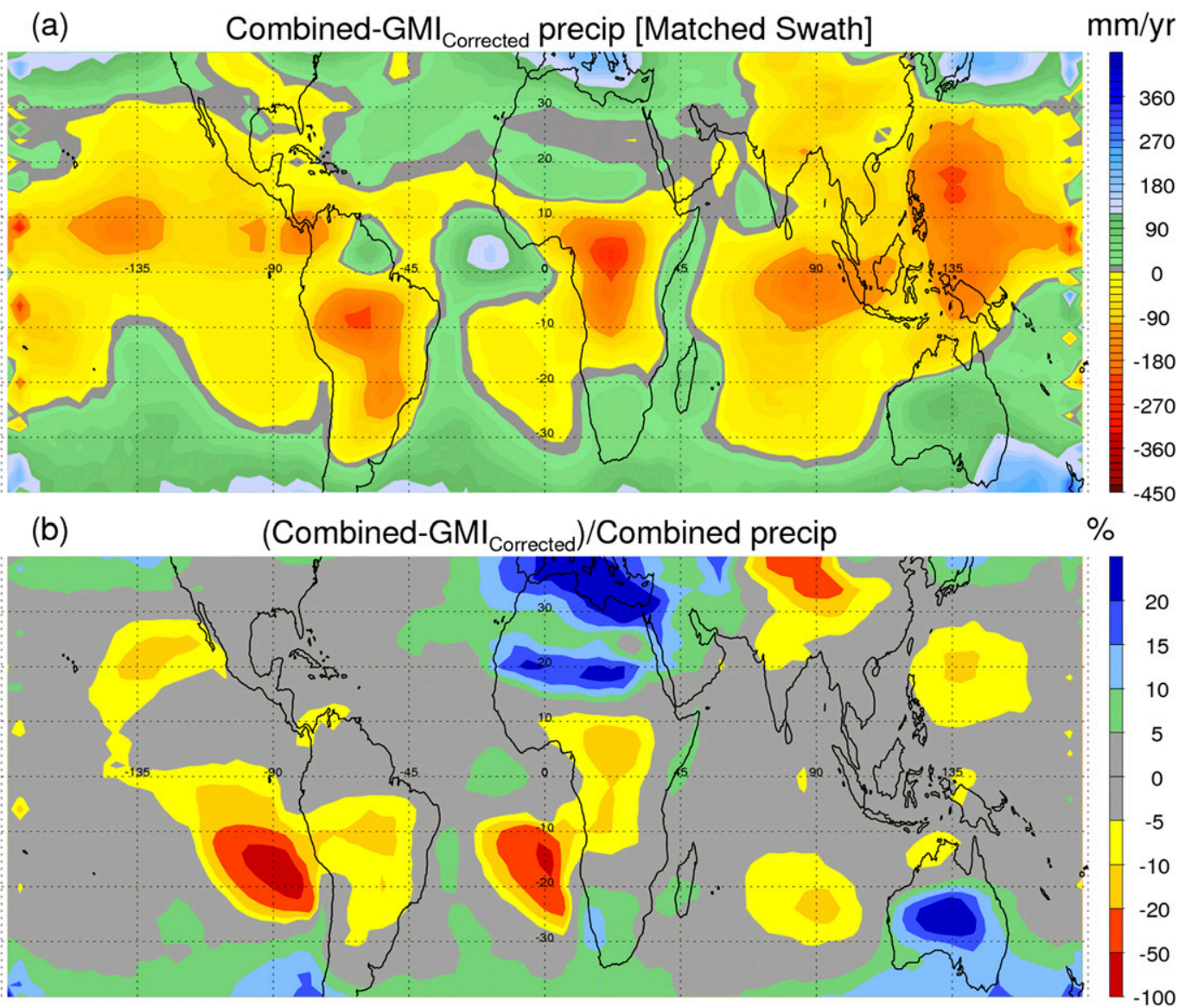

FIG. 9. Geographical distribution of (a) differences and (b) percentage differences between mean unconditional precipitation rates estimated by Combined and GMI. The distribution is generated on a $5^{\circ} \times 2^{\circ}$ longitudes and latitudes grid. The GMI products are used only matched swath with combined (DPR).

Hemisphere $\left(10^{\circ}-25^{\circ} \mathrm{S}\right)$ during April to October, GMI overestimates the Combined by about $25 \%$. During the Northern Hemispheric winter and Southern Hemispheric summer, GMI is relatively consistent with the Combined (Fig. 11a). Some of the seasonal and zonal discrepancies between the GMI and Combined retrievals are overcome with the bias correction approach. The joint seasonal and zonal variations of percentage differences between the bias corrected GMI and the Combined is presented in Fig. 11b. Large biases $(\sim 20 \%)$ over $10^{\circ}-25^{\circ} \mathrm{S}$ during April to October have been reduced to $\sim 5 \%$. Many of the biases in tropical regions are now within $10 \%$, which is almost half of the previous biases. Significant improvements of GMI biases over Northern Hemispheric midlatitudes are also observed. The GMI biases $(25 \%)$ over those regions are reduced to $10 \%$ or less, except for a small area $\left(25^{\circ}-30^{\circ} \mathrm{N}\right)$ during summer. However, some of the winter season biases over certain latitudes such as $30^{\circ}-40^{\circ} \mathrm{N}$, and $25^{\circ}-40^{\circ} \mathrm{S}$ are not improved.
Those are probably the Australian and Mediterranean biases that have been discussed earlier.

\section{Summary}

This study analyzes the performance of surface precipitation estimates from the GMI with respect to the near surface precipitation estimated by the GPM Combined product over $40^{\circ} \mathrm{S}-40^{\circ} \mathrm{N}$. In general, GMI and Combined precipitation estimates show consistent geographical distributions on a global scale. However, the mean zonal precipitation rate over $40^{\circ} \mathrm{S}-40^{\circ} \mathrm{N}$ from GMI is $17 \%$ (4\%) more than the Combined over land (ocean). The GMI estimated precipitation is closer to the Combined over ocean than it is over land. Over land, especially central Africa, the Himalayan region, and central South America, GMI estimates 30\% more precipitation than the Combined. Over the Mediterranean, GMI estimates about $20 \%$ less precipitation than the Combined. 

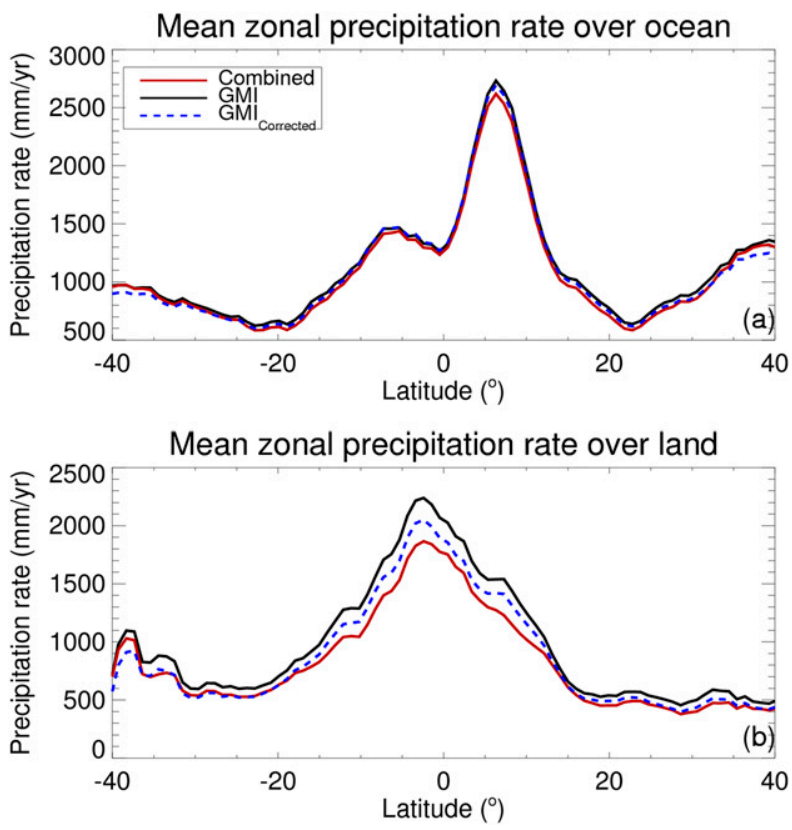

FIG. 10. Mean zonal precipitation rates as a function of latitude (a) over ocean and (b) over land, estimated by Combined (red curve), GMI (black curve), and bias corrected GMI (blue dashed curve).

The uncertainties in GMI are further analyzed based on a pixel-to-pixel comparison and the precipitation system properties such as system size and min89PCT. The GMI shows higher occurrences for lighter $\left(<1 \mathrm{~mm} \mathrm{~h}^{-1}\right)$ and lower occurrences for heavy precipitation $\left(>10 \mathrm{~mm} \mathrm{~h}^{-1}\right)$ over both land and ocean. The GMI tends to underestimate precipitation volume for small systems $\left(<200 \mathrm{~km}^{2}\right)$ and tends to overestimate for large $\left(>2000 \mathrm{~km}^{2}\right)$ systems. GMI probably detects large areas of weak precipitation that are missed by DPR because the minimum detectable signal limits the precipitation rates that can be measured. GMI also has serious issues detecting warm rainfall over the ocean because there are insufficient or no ice scattering signatures in these types of systems.

This study shows that the GMI precipitation uncertainties are associated with ice scattering signatures and storm size. Rather than treating pixels independently, GMI biases can be reduced by considering precipitation systems. A simple bias correction approach is developed based on the area and min89PCT of precipitation system. The GMI precipitation is modified by considering the bias factors, which is the ratio of Combined and GMI precipitation volume in each bin of area and min89PCT over land and ocean separately. The bias corrected GMI shows that the GMI precipitation biases can be improved by $20 \%-30 \%$ over central Africa, the Himalayan region, and central South America. The mean zonal bias corrected precipitation over $40^{\circ} \mathrm{S}-40^{\circ} \mathrm{N}$ land shows only $7 \%$ bias when compared with the Combined precipitation, which is a significant improvement from the previous estimate $(17 \%)$. The zonal and seasonal variation of the bias corrected GMI shows that this simple bias correction approach is more promising over land, and improves precipitation estimates in all seasons in tropics. However, there are some regions, such as the Mediterranean and stratocumulus regions, that this method does not show such promising improvements. Over these regions, using precipitation system information to reduce biases is still a challenge.

While this study summarizes uncertainties related to the GPM GMI precipitation retrieval and then develops
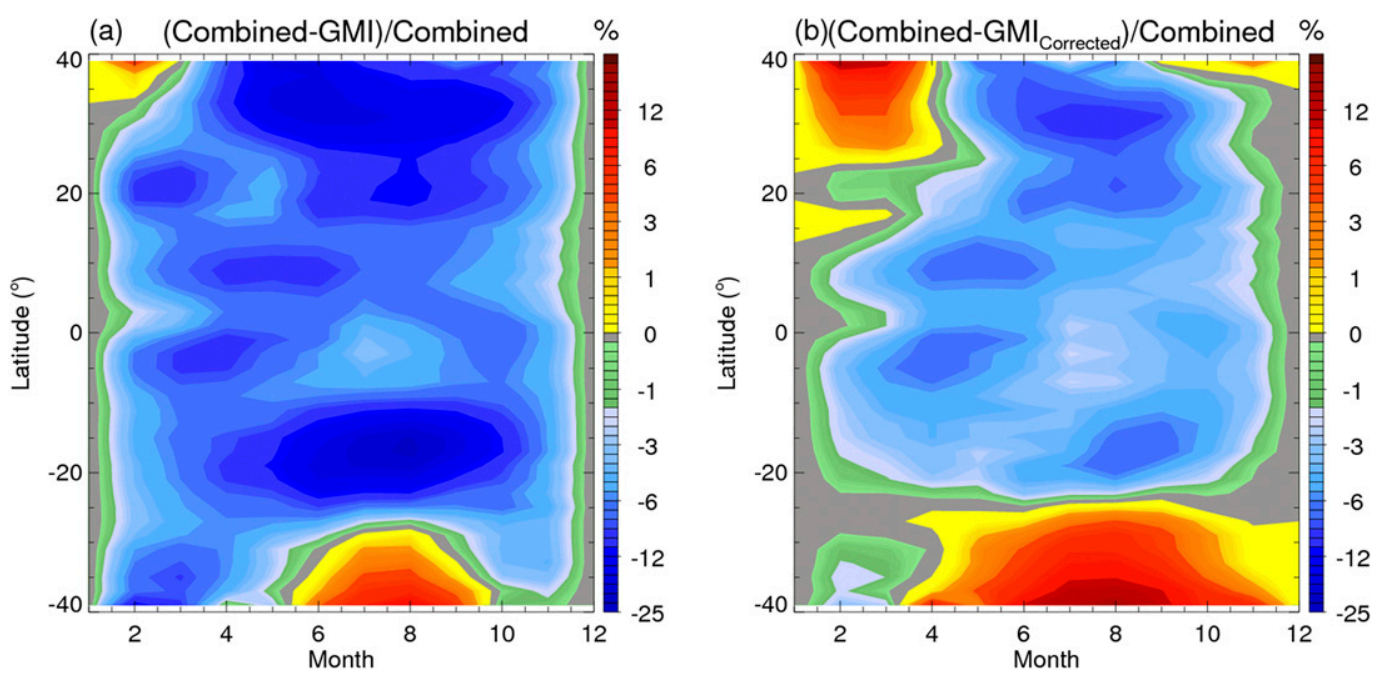

FIG. 11. (a) Joint zonal and seasonal variation of percentage differences between Combined and GMI precipitation. (b) As in (a), but between Combined and bias corrected GMI precipitation. 
a methodology to correct the bias associated with it, a few caveats and future work should be highlighted. First, the focus of this study is over relatively warm surface of the globe where, the majority of precipitation falls as liquid, and thus the study domain is restricted to $40^{\circ} \mathrm{S}-40^{\circ} \mathrm{N}$. The precipitation systems beyond the study domain are different than the tropics and subtropics, and it is not appropriate to implement the same methodology to the higher latitudes. Figure 11 also implies the underestimation of the wintertime precipitation at latitudes greater than $30^{\circ}$. It is important to further examine the relationship between retrieval biases and surface temperatures. Snow retrieval using passive microwave sensors is still a challenge at mid- to high latitudes, so a different approach may be required to deal with higher-latitude precipitation systems, which warrants a future work. Second, the bias correction approach implements minimum $89 \mathrm{GHz}$ PCT as one of the major parameters because of its comparable field of view with the DPR. The lower-frequency channels such as 10 or $19 \mathrm{GHz}$ may contribute more to the retrieval results especially over ocean, where the most important signature is emission. How to utilize these channels in the precipitation features is worthy of considering in the future. Last, the bias correction approach introduced here is primarily intended to tune the GMI precipitation retrievals over the tropics and subtropics. To implement this approach to the other passive microwave radiometer constellation members still need to adjust to the different resolutions, frequencies, and sensitivities and further work needs to be done. Besides some caveats, this study demonstrates the potential of improving the precipitation retrievals by using the precipitation features information, which also indicates the worthiness of including precipitation features information in the GPROF database and may be treated as an ancillary parameter to further stratify the database.

Acknowledgments. This research was supported by NASA Precipitation Measurement Mission grants NNX16AD76G under the direction of Dr. Ramesh Kakar and NNX16AH74G under the direction of Dr. Erich Stocker. Thanks to the Precipitation Processing System (PPS) team at NASA Goddard Space Flight Center, Greenbelt, MD, for data processing assistance. The GPM precipitation feature data can be downloaded from http:// atmos.tamucc.edu/trmm/data/.

\section{REFERENCES}

Allen, M. R., and W. J. Ingram, 2002: Constraints on future changes in climate and the hydrologic cycle. Nature, 419, 228-232, https://doi.org/10.1038/nature01092.
Carr, N., and Coauthors, 2015: The influence of surface and precipitation characteristics on TRMM Microwave Imager rainfall retrieval uncertainty. J. Hydrometeor., 16, 1596-1614, https://doi.org/10.1175/JHM-D-14-0194.1.

Cecil, D. J., E. J. Zipser, and S. W. Nesbitt, 2002: Reflectivity, ice scattering, and lightning characteristics of hurricane eyewalls and rainbands. Part I: Quantitative description. Mon. Wea. Rev., 130, 769-784, https://doi.org/10.1175/1520-0493(2002) $130<0769:$ RISALC $>2.0 . \mathrm{CO} ; 2$.

Chahine, M. T., 1992: The hydrological cycle and its influence on climate. Nature, 359, 373-380, https://doi.org/10.1038/359373a0.

Costa, I. C., L. A. T. Machado, and C. Kummerow, 2018: An examination of microwave rainfall retrieval biases and their characteristics over the Amazon. Atmos. Res., 213, 323-330, https://doi.org/10.1016/j.atmosres.2018.06.011.

Draper, D. W., D. A. Newell, F. J. Wentz, S. Krimchansky, and G. M. Skofronick-Jackson, 2015: The global precipitation measurement (GPM) microwave imager (GMI): Instrument overview and early on-orbit performance. IEEE J. Sel. Top. Appl. Earth Obs. Remote Sens., 8, 3452-3462, https://doi.org/ 10.1109/JSTARS.2015.2403303.

Ferraro, R. R., N. C. Grody, and G. F. Marks, 1994: Effects of surface conditions on rain identification using the DMSPSSM/I. Remote Sens. Rev., 11, 195-209, https://doi.org/10.1080/ 02757259409532265.

_ methodology for passive microwave precipitation retrieval algorithms. J. Atmos. Sci., 55, 1583-1600, https://doi.org/ 10.1175/1520-0469(1998)055<1583:ASMFPM>2.0.CO;2.

— , and Coauthors, 2013: An evaluation of microwave land surface emissivities over the continental United States to benefit GPM-Era precipitation algorithms. IEEE Trans. Geosci. Remote Sens., 51, 378-398, https://doi.org/10.1109/ TGRS.2012.2199121.

Fulton, R., and G. M. Heymsfield, 1991: Microphysical and radiative characteristics of convective clouds during COHMEX. J. Appl. Meteor., 30, 98-116, https://doi.org/10.1175/1520-0450(1991) $030<0098$ :MARCOC $>2.0 . \mathrm{CO} ; 2$.

Gopalan, K., N. Y. Wang, R. Ferraro, and C. Liu, 2010: Status of the TRMM 2A12 land precipitation algorithm. J. Atmos. Oceanic Technol., 27, 1343-1354, https://doi.org/10.1175/ 2010JTECHA1454.1.

Grecu, M., W. S. Olson, S. J. Munchak, S. Ringerud, L. Liao, Z. Haddad, B. L. Kelley, and S. F. Mclaughlin, 2016: The GPM combined algorithm. J. Atmos. Oceanic Technol., 33, 2225-2245, https://doi.org/10.1175/JTECH-D-16-0019.1.

Grody, N. C., 1991: Classification of snow cover and precipitation using the Special Sensor Microwave Imager. J. Geophys. Res., 96, 7423-7435, https://doi.org/10.1029/91JD00045.

Hamada, A., and Y. N. Takayabu, 2016: Improvements in detection of light precipitation with the Global Precipitation Measurement dual-frequency precipitation radar (GPM DPR). J. Atmos. Oceanic Technol., 33, 653-667, https:// doi.org/10.1175/JTECH-D-15-0097.1.

Hou, A. Y., and Coauthors, 2014: The Global Precipitation Measurement Mission. Bull. Amer. Meteor. Soc., 95, 701-722, https://doi.org/10.1175/BAMS-D-13-00164.1.

Huffman, G. J., R. F. Adler, B. Rudolf, U. Schneider, and P. R. Keehn, 1995: Global precipitation estimates based on a technique for combining satellite-based estimates, rain gauge analysis, and NWP model precipitation information. J. Climate, 8, 1284-1295, https://doi.org/10.1175/1520-0442(1995)008<1284: GPEBOA $>2.0 . \mathrm{CO}$;2. 
Kidd, C., and V. Levizzani, 2011: Status of satellite precipitation retrievals. Hydrol. Earth Syst. Sci., 15, 1109-1116, https:// doi.org/10.5194/hess-15-1109-2011.

Kummerow, C., W. S. Olson, and L. Giglio, 1996: A simplified scheme for obtaining precipitation and vertical hydrometeor profiles from passive microwave sensors. IEEE Trans. Geosci. Remote Sens., 34, 1213-1232, https://doi.org/10.1109/36.536538.

_ - W. Barnes, T. Kozu, J. Shiue, and J. Simpson, 1998: The Tropical Rainfall Measuring Mission (TRMM) sensor package. J. Atmos. Oceanic Technol., 15, 809-817, https://doi.org/10.1175/ 1520-0426(1998)015<0809:TTRMMT>2.0.CO;2.

— , and Coauthors, 2001: The evolution of the Goddard Profiling Algorithm (GPROF) for rainfall estimation from passive microwave sensors. J. Appl. Meteor., 40, 1801-1820, https://doi.org/ 10.1175/1520-0450(2001)040<1801:TEOTGP > 2.0.CO;2.

— , S. Ringerud, J. Crook, D. Randel, and W. Berg, 2011: An observationally generated a priori database for microwave rainfall retrievals. J. Atmos. Oceanic Technol., 28, 113-130, https://doi.org/10.1175/2010JTECHA1468.1.

Kummerow, C. D., D. L. Randel, M. Kulie, N. Y. Wang, R. Ferraro, S. Joseph Munchak, and V. Petkovic, 2015: The evolution of the Goddard profiling algorithm to a fully parametric scheme. J. Atmos. Oceanic Technol., 32, 2265-2280, https://doi.org/10.1175/JTECH-D-15-0039.1.

Liu, C., 2016: GPM precipitation feature database. Tech. Rep., 15 pp., http://atmos.tamucc.edu/trmm/data/document/GPM_database_ description_1.0_201601.pdf.

—_, and E. J. Zipser, 2009: "Warm rain" in the tropics: Seasonal and regional distributions based on $9 \mathrm{yr}$ of TRMM data J. Climate, 22, 767-779, https://doi.org/10.1175/2008JCLI2641.1.

_- and E. Zipser, 2014: Differences between the surface precipitation estimates from the TRMM Precipitation Radar and passive microwave radiometer version 7 products. J. Hydrometeor., 15, 2157 2175, https://doi.org/10.1175/JHM-D-14-0051.1.

— E. J. Zipser, D. J. Cecil, S. W. Nesbitt, and S. Sherwood, 2008: A cloud and precipitation feature database from nine years of TRMM observations. J. Appl. Meteor. Climatol., 47, 2712-2728, https://doi.org/10.1175/2008JAMC1890.1.

Masunaga, H., T. Iguchi, R. Oki, and M. Kachi, 2002: Comparison of rainfall products derived from TRMM microwave imager and precipitation radar. J. Appl. Meteor., 41, 849-862, https://doi.org/ 10.1175/1520-0450(2002)041<0849:CORPDF >2.0.CO;2.

Mugnai, A., and E. A. Smith, 1988: Radiative transfer to space through a precipitating cloud at multiple microwave frequencies. Part I: Model description. J. Appl. Meteor., 27, 1055-1073, https:// doi.org/10.1175/1520-0450(1988)027<1055:RTTSTA >2.0.CO;2.

Munchak, S. J., and G. Skofronick-Jackson, 2013: Evaluation of precipitation detection over various surfaces from passive microwave imagers and sounders. Atmos. Res., 131, 81-94, https://doi.org/10.1016/j.atmosres.2012.10.011.

Nesbitt, S. W., E. J. Zipser, and C. D. Kummerow, 2004: An examination of version- 5 rainfall estimates from the TRMM Microwave Imager, Precipitation Radar, and rain gauges on global, regional, and storm scales. J. Appl. Meteor., 43, 1016-1036, https://doi.org/ 10.1175/1520-0450(2004)043<1016:AEOVRE > 2.0.CO;2.

Njoku, E. G., 1982: Passive microwave remote sensing of the Earth from space-A review. Proc. IEEE, 70, 728-750, https:// doi.org/10.1109/PROC.1982.12380.

Olson, W. S., H. Masunaga, and GPM Combined Radar-Radiometer Algorithm Team, 2016: GPM combined radar-radiometer precipitation algorithm theoretical basis document (version 4). Tech. Rep., 63 pp., https://pmm.nasa.gov/sites/default/files/ document_files/Combined_algorithm_ATBD.V04.rev_.pdf.
Petersen, W. A., P. E. Kirstetter, J. Wang, D. B. Wolff, and A. Tokay, 2019: The GPM GV Program. Tech. Doc., 21 pp., https:// ntrs.nasa.gov/archive/nasa/casi.ntrs.nasa.gov/20190000321.pdf.

Petković, V., and C. D. Kummerow, 2015: Performance of the GPM passive microwave retrieval in the Balkan flood event of 2014. J. Hydrometeor., 16, 2501-2518, https://doi.org/10.1175/ JHM-D-15-0018.1.

Prigent, C., 2010: Precipitation retrieval from space: An overview. C. R. Geosci., 342, 380-389, https://doi.org/10.1016/ j.crte.2010.01.004.

Randall, D. A., and Coauthors, 2007: Climate models and their evaluation. Climate Change 2007: The Physical Science Basis, S. Solomon et al., Eds., Cambridge University Press, 589-662.

Skofronick-Jackson, G., and Coauthors, 2017: The Global Precipitation Measurement (GPM) mission for science and society. Bull. Amer. Meteor. Soc., 98, 1679-1695, https://doi.org/ 10.1175/BAMS-D-15-00306.1.

—, D. Kirschbaum, W. Petersen, G. Huffman, C. Kidd, E. Stocker, and R. Kakar, 2018: The Global Precipitation Measurement (GPM) mission's scientific achievements and societal contributions: Reviewing four years of advanced rain and snow observations. Quart. J. Roy. Meteor. Soc., 144, 27-48, https://doi.org/10.1002/qj.3313.

Spencer, R. W., 1984: Satellite passive microwave rain rate measurement over croplands during spring, summer and fall. $J$. Climate Appl. Meteor., 23, 1553-1562, https://doi.org/10.1175/ 1520-0450(1984)023<1553:SPMRRM > 2.0.CO;2.

— H. Hoodman, and R. Hood, 1989: Precipitation retrieval over land and ocean with the SSM/I: Identification and Characteristics of the Scattering Signal. J. Atmos. Oceanic Technol., 6, 254-273, https://doi.org/10.1175/1520-0426(1989)006<0254: PROLAO $>2.0 . C O ; 2$.

Toracinta, E. R., D. J. Cecil, E. J. Zipser, and S. W. Nesbitt, 2002: Radar, passive microwave, and lightning characteristics of precipitating systems in the tropics. Mon. Wea. Rev., 130, 802-824, https://doi.org/ 10.1175/1520-0493(2002)130<0802:RPMALC >2.0.CO;2.

Trenberth, K. E., A. Dai, R. M. Rasmussen, and D. B. Parsons, 2003: The changing character of precipitation. Bull. Amer. Meteor. Soc., 84, 1205-1218, https://doi.org/10.1175/BAMS-84-9-1205.

Wall, C., C. Liu, and E. Zipser, 2013: A climatology of tropical congestus using CloudSat. J. Geophys. Res. Atmos., 118, 6478-6492, https://doi.org/10.1002/jgra.50573.

Wang, N.-Y., C. Liu, R. Ferraro, D. Wolff, E. Zipser, and C. Kummerow, 2009: TRMM 2A12 land precipitation product - Status and future plans. J. Meteor. Soc. Japan, 87A, 237-253, https://doi.org/10.2151/jmsj.87A.237.

Wilheit, T. T., 1986: Some comments on passive microwave measurement of rain. Bull. Amer. Meteor. Soc., 67, 1226-1232, https:// doi.org/10.1175/1520-0477(1986)067<1226:SCOPMM>2.0.CO;2.

_ J. S. Theon, W. E. Shenk, L. J. Allison, and E. B. Rodgers, 1976: Meteorological interpretations of the images from the Nimbus 5 electrically scanned microwave radiometer. J. Appl. Meteor., 15, 166-172, https://doi.org/10.1175/1520-0450(1976) 015<0166:MIOTIF>2.0.CO;2.

—, A. T. C. Chang, and L. S. Chiu, 1991: Retrieval of monthly rainfall indices from microwave radiometric measurements using probability distribution functions. J. Atmos. Oceanic Technol., 8, 118-136, https://doi.org/10.1175/1520-0426(1991) 008<0118:ROMRIF $>2.0 . \mathrm{CO} ; 2$.

Zhang, J., and Coauthors, 2016: Multi-Radar Multi-Sensor (MRMS) quantitative precipitation estimation: Initial operating capabilities. Bull. Amer. Meteor. Soc., 97, 621-638, https://doi.org/10.1175/BAMS-D-14-00174.1. 